\title{
Глаголы движения shkoj 'идти' и vij 'приходить' в албанском языке: корпусное исследование
}

\author{
К. С. Клименок \\ Санкт-Петербургский государственный университет; ksenchenk@yandex.ru
}

Аннотация. В работе рассматриваются особенности лексической семантики и способы выражения цели и источника при основных албанских глаголах движения shkoj 'идти' и vij 'приходить'. Исследование проведено на материале Албанского национального корпуса (АНК) с применением подходов, используемых в работах по лингвистической типологии, грамматической и лексической семантике глаголов движения.

Глаголы shkoj и vij анализируются с точки зрения их ориентации на цель или источник (goal-oriented, source-oriented) и с учетом общетипологической тенденции к эксплицитному заполнению валентности цели (goal-bias). Способы заполнения валентностей цели и источника при этих глаголах рассматриваются как на примере их сочетаний с предложными конструкциями, кодирующими разные компоненты маршрута (в частности, с наиболее частотными пространственными предлогами албанского языка $n g a$ 'от, из; в, к', $t e(k)$ 'к', $n \ddot{e}$ 'в'), так и в конструкциях без соответствующих аргументов на поверхностно-синтаксическом уровне. Отдельно рассматриваются конструкции с глаголами shkoj/vij и предлогом $n g a$, который способен кодировать и цель и источник (source/goal ambuguity). В этой части исследования особенности употребления глаголов shkoj и vij описываются с учетом позиции в ситуации говорящего / наблюдателя.

Ключевые слова: албанский язык, корпусное исследование, глаголы движения, лексическая семантика, аргументная структура, цель, источник, валентность, режим интерпретации.

\section{Verbs of motion shkoj 'go' and vij 'come' in Albanian: A corpus study}

\section{K. S. Klimenok}

St. Petersburg State University; ksenchenk@yandex.ru

Abstract. The paper examines the lexical semantics and the patterns of encoding the goal and source of motion with the main Albanian motion verbs, shkoj 'go' and 
vij 'come'. The research was based on the Albanian National Corpus (ANC) using approaches applied in linguistic typology and in works on the grammatical and lexical semantics of motion verbs.

The verbs shkoj and vij are analyzed in terms of their orientation on the goal or source of motion (goal-oriented, source-oriented) and with the consideration of the general typological tendency to explicitly fill the goal valency, known as goal-bias. The ways of filling in the goal and source valencies of these verbs are considered both in combinations with prepositional constructions expressing the different components of path (in particular, with the most frequent spatial prepositions of the Albanian language: $n g a$ 'from; to', $t e(k)$ 'to', and $n \ddot{e}$ 'in') and in constructions without the corresponding arguments at the surface level. Special attention is paid to the constructions with the verbs shkoj / vij and the preposition $n g a$, which can encode both the goal and the source of motion (source / goal ambuguity). In this part of the study, the use of the verbs shkoj and vij is described considering the position of the speaker/ observer in the situation.

Keywords: Albanian language, corpus study, motion verbs, lexical semantics, argument structure, goal, source, valency, interpretation mode.

\section{1. Введение}

В настоящей статье представлены некоторые результаты исследования, посвященного особенностям семантики и актантной структуры глаголов движения в албанском языке. В широком смысле к глаголам движения или перемещения принято относить любые лексемы, которые обозначают изменение местоположения субъекта в пространстве ${ }^{1}$. В русском языке примерами таких лексем могут послужить слова типа идти, бежать, пльлть и т. д. [Майсак 2005: 101-117]. В албанском языке в качестве примера можно привести глаголы fluturoj ‘лететь', vrapoj ‘бежать', shkoj 'идти / ехать', vij 'приходить / приезжать’ и др. В нашей статье мы подробно остановимся на рассмотрении двух последних, vij и shkoj, которые являются базовыми глаголами

${ }^{1}$ В традиционной русистике глаголами движения принято называть пары глаголов типа бежать - бегать, идти - ходить, которые противопоставлены по однократности / многократности движения или по его (разно)направленности [Левонтина, Шмелев 2005: 78]. Вопросы, связанные с данной спецификой, в статье не рассматриваются. 
перемещения в албанском языке, подобно глаголам соте и gо в английском, а также приходить и идти в русском.

В языках мира в употреблении глаголов типа алб. vij и shkoj, англ. come и go, рус. приходить и идти обнаруживается значительная вариативность с точки зрения того, как учитывается позиция в ситуации говорящего (или наблюдателя) и адресата сообщения. Зачастую эти глаголы являются дейктически ориентированными. Так, английский глагол соте, как показано в исследовании Ч. Филлмора, требует, чтобы один из участников ситуации находился на момент совершения действия в точке отсчета; в противном случае должен быть использован глагол go [Fillmore 1971/1983: 221]. Русский глагол приходить менее чувствителен к позиции говорящего и адресата, чем английский соте, и в целом русские глаголы приходить и идти, по всей видимости, менее ориентированы на положение говорящего или наблюдателя, хотя

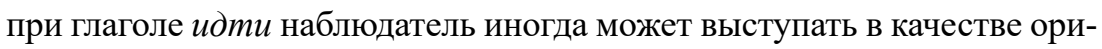
ентира [Майсак 2005: 112-113; Рахилина 2008: 316-317].

Кроме того, глаголы такого типа различаются между собой (и неодинаково ведут себя в разных языках) на основании того, на какую точку маршрута — начальную или конечную - они ориентированы в большей степени и, соответственно, какая из валентностей - начальной или конечной точки - чаще оказывается заполненной. В частности, при употреблении английского глагола go пункт отправления, как правило, известен и требуется дополнительная информация о конечной точке, а глагол соте, напротив, требует указания на источник прибытия. Два соответствующих класса глаголов названы «ориентированными на начальную точку движения» (англ. source-oriented) и «ориентированными на конечную точку движения» (англ. goal-oriented) [Fillmore 1971/1983: 220]. Помимо этого, выделяются так называемые глаголы «чистого перемещения», например русский глагол идти, для которых обе валентности являются факультативными [Майсак 2005: 114; Рахилина 2008: 315].

Цель настоящей работы состоит в том, чтобы описать особенности лексической семантики албанских глаголов vij и shkoj (ориентация на начальную или конечную точку маршрута, употребление в зависимости от положения говорящего или наблюдателя), а также изучить способы кодирования цели и источника и стратегии заполнения соответствующих валентностей при данных глаголах.

Исследование выполнено на материале Албанского национального корпуса [АНК 2011-2016] (далее в тексте и при указании источника 
примеров - АНК), который, по состоянию на 25.05.2019, содержит 31,12 млн словоупотреблений. АНК включает несколько подкорпусов с текстами различных типов и жанров на современном литературном языке: пресса (газеты Zëri, Koha, Gazeta shqiptare), художественные тексты (романы, рассказы), нехудожественные тексты (мемуарная проза, эссеистика, религиозные тексты, учебники и научные тексты, официальные документы), поэзия.

Используя АНК, мы составили две случайные выборки по 100 примеров с глаголами shkoj и vij, выполнив последовательный поиск каждого из них по лемме, без указания на наличие или отсутствие аргумента при глаголе. В полученных выборках 3 примера с глаголом shkoj и 16 с глаголом vij были интерпретированы как «шум» и далее не рассматривались ${ }^{2}$. Соответственно, конечный размер анализируемых выборок составил 97 и 84 примера.

Для более детального изучения особенностей конструкций с предлогом $n g a$ дополнительно были собраны и проанализированы две выборки примеров из АНК: 238 примеров с сочетанием «shkoj + nga» и 90 - с сочетанием «vij + nga».

Примеры из вышеописанных выборок анализируются в нижеследующих разделах статьи. В Разделе 2 обсуждается семантика глаголов shkoj и vij и влияние, которое она оказывает на аргументную структуру данных глаголов с точки зрения выражения аргументов «цель» и «источник» (2.2), а также описываются и анализируются возможные способы заполнения соответствующих валентностей этих глаголов (2.3). В Разделе 3 рассматриваются конструкции с предлогом $n g a$ 'от, из; в, к’, послужившие диагностическим контекстом для данной работы. Анализ этого материала позволяет дополнить заключения предыдущего раздела. Раздел 4 содержит общие выводы, сделанные на основе проанализированного материала.

2 В эту категорию попали случаи омонимии с формами других глаголов или существительных. Например, формы глагола vё 'класть, ставить', омонимичные формам vij (IPF.3PL vinin), а также употребления прилагательного i/e shkuar 'прошлый’, образованного от причастия глагола shkoj. К «шуму» мы отнесли и фрагмент включенного в АНК текста грамматики албанского языка, где приводилась парадигма спряжения глагола vij, а также примеры типа vi-nte e dobëso-hej (приходить-IPF.3SG и ослабевать-INACT.IPF.3SG) 'постепенно ослабевал', где vij употребляется в составе конструкции, обозначающей постепенное нарастание признака [Жугра 1986]. 


\section{2. Особенности употребления албанских глаголов движения shkoj и vij}

\section{1. Анализ материала исследования}

В ходе анализа материала примеры из двух случайных выборок с глаголами shkoj и vij были охарактеризованы по таким параметрам, как 1) тип употребления, 2) способ оформления аргументов «цель» и «источник», 3) значение предлога (в предложных конструкциях), наречия или местоимения, кодирующего цель или источник, 4) способ заполнения валентностей цели и источника при глаголе.

Тип употребления определялся в соответствии с значением глаголов shkoj и vij в полученных примерах. В зависимости от того, описывают ли эти глаголы ситуацию перемещения в пространстве ${ }^{3}$ или выражают иное значение, основанное на метафоре движения ${ }^{4}$, мы разделили примеры на два типа, условно обозначенные как «пространственные» и «непространственные», или переносные употребления (см. примеры (1) и (2) ниже). Распределение примеров в выборках по указанным типам представлено в Таблице 1 (с. 132).

$\begin{array}{lll}\text { (1) Une } & \text { ja-m } & \text { gazetar, } \\ \text { 1sG.NOM } & \text { быть-PRS.1SG } & \text { журналист.NOM.SG.INDF }\end{array}$

\begin{tabular}{|c|c|c|c|}
\hline$k a-m$ & ardhur & nga & Kosov-a. \\
\hline иметь-PRS.1SG & приходить.РТСР & PREP & Косово-NOM.SG.DEF \\
\hline
\end{tabular}

${ }^{3}$ «Типичная ситуация движения / перемещения состоит в том, что основной участник ситуации последовательно изменяет свое положение в пространстве, двигаясь сам либо под воздействием внешнего каузатора. 〈... Основного участника такой ситуации мы будем в дальнейшем называть субъектом движения. 〈...〉 Участки пространства, занимаемые субъектом в ходе движения, образуют определенный маршрут, или путь (path) перемещения» [Майсак 2005: 102-103].

${ }^{4}$ Основными и наиболее детально изученными типами метафорических переносов являются представление временны́х отношений и описание изменений состояния в терминах пространственных отношений: ВРЕМЯ — ЭТО ДВИЖЕНИЕ, ИЗМЕНЕНИЕ — ЭТО ДВИЖЕНИЕ [Майсак 2005: 115]. 
Таблица 1. Распределение примеров с глаголами shkoj и vij по типу употребления

Table 1. Distribution of examples with the verbs shkoj and vij by type of use

\begin{tabular}{|l|c|c|c|}
\hline \multicolumn{1}{|c|}{ Тип употребления } & \multicolumn{3}{c|}{$\begin{array}{c}\text { Количество } \\
\text { примеров }\end{array}$} \\
\cline { 2 - 4 } & shkoj & $\boldsymbol{v i j}$ & Всего \\
\hline $\begin{array}{l}\text { Конструкции с пространственным значением } \\
\text { («пространственные») }\end{array}$ & 50 & 45 & 95 \\
\hline $\begin{array}{l}\text { Конструкции с переносным, непространственным } \\
\text { значением («непространственные») }\end{array}$ & 47 & 39 & 86 \\
\hline Всего & 97 & 84 & 181 \\
\hline
\end{tabular}

$\begin{array}{lll}\text { Vler- } a & e & \text { këtyre } \\ \text { стоимость-NOM.SG.DEF } & \text { F.NOM.SG } & \text { эTOT.GEN.PL }\end{array}$

pajisje-ve të vjedhur-a shko-n

устройство-GEN.PL GEN.PL украденный-F.PL идти-PRS.3SG

nё rreth 200 mijë euro.

PREP PREP 200 тысяча евpO.ACC.PL.INDF

'Стоимость этих украденных устройств доходит примерно до 200 тысяч евро’. [AHК: Zёri. 2013]

Поскольку, согласно одной из распространенных точек зрения на семантическое описание, пространственные значения глаголов, предлогов и наречий являются семантически базовыми по отношению к непространственным, описание непространственных употреблений может опираться на пространственные употребления [Рахилина 2008: 290-291]. В нашей выборке между пространственными и непространственными конструкциями не было обнаружено различий с точки зрения остальных параметров, поэтому далее мы будем использовать примеры обоих типов в нашем анализе ${ }^{5}$.

С точки зрения способа оформления аргументов, в случайных выборках были обнаружены следующие типы конструкций с глаголами vij и shkoj: 1) без синтаксически выраженных аргументов «цель»

${ }^{5}$ В более раннем исследовании [Клименок 2018], посвященном употреблению предлога $n g a$ в конструкциях с глаголами движения shkoj и vij и глаголов зрительного восприятия, этот параметр специально проверялся и также не было обнаружено различий в употреблении пространственных и непространственных конструкций. 
и «источник» при глаголе, 2) с одним или двумя аргументами, которые вводятся различными предлогами, 3) с одним или двумя аргументами, выраженными дейктическими наречиями, а также 4) с одним представленным на поверхностно-синтаксическом уровне дативным аргументом «цель», который может быть выражен существительным или местоимением. Подробнее соотношение этих способов рассмотрено в подразделе 2.2.

В настоящей работе не будут подробно рассмотрены все встретившиеся в выборках пространственные конструкции с предлогами (ср., например, предлоги, способные оформлять конечный пункт: pёr 'для, к', drejt 'к', mbi ‘над, к', ndёr 'среди, к', pranё 'рядом, возле, к'). Мы сосредоточимся на наиболее частотных: nga 'от, из; в, к', te(k) 'к' и пё ‘в, к'. Согласно «Словарю современного албанского языка» [FGjSSh 1980], все три предлога многозначны и, наряду с основными пространственными, могут выражать ряд периферийных, непространственных значений. Интересующие нас значения начального и конечного пункта при глаголах движения кодируются этими предлогами следующим образом. Предлог пё указывает на место, где субъект оказывается в результате движения или действия: $u=n g j i t-\ddot{e} n$ nё majë (INACT= поднять-AOR.3PL PREP вершина.ACC.SG.INDF) 'поднялись на вершину'. Посредством $t e(k)$ также может описываться указание на конечную точку: erdh-i te gjysh-i (приходить.AOR-AOR.3SG PREP дедушка-NOM.SG.DEF) 'пришел к дедушке'. Для $n g a$ характерно указание как на пункт отправления или источник движения (erdh-ёn nga Durrës-i (приходить.AOR-AOR.3SG PREP Дурpec-NOM.SG.DEF) 'приехали из Дурpeca'), так и на пункт назначения или цель (shkua-n nga lum-i (идTИ-AOR.3PL PREP peка-NOM.SG.DEF) 'пришли к реке'), причем источник в албанском языке может выражаться только с помощью двух предлогов: упомянутого выше nga и предлога prej 'из, от', который имеет исключительно значение источника и является менее частотным. Типологически ситуация с предлогом nga представляет собой хороший пример характерной для некоторых языков мира омонимии цели и источника (англ. source / goal ambiguity) [Nikitina 2009: 1116], и, судя по этой особенности употребления $n g a$, албанский является одним из тех языков, где цель и источник (а иногда и местонахождение) могут маркироваться одинаково.

О распространенности предлогов $n g a, n е ̈$ и $t e(k)$ в сочетании с глаголами движения shkoj и vij в албанском языке можно судить по их употреблению в текстах АНК, которое показано в Таблицее 2 (с. 134). 
Для получения данных, представленных в Таблище 2, мы выполнили поиск по корпусу конструкций с глаголами shkoj/vij и предлогами $n g a / n \ddot{e} / t e(k)$, где указанные предлоги расположены на расстоянии «от одного до двух слов» от глагола, т. е. непосредственно после глагола или через одно слово от него (бо́льшая отдаленность предполагает увеличение количества «шума»), и оценили их общее количество (левая часть таблицы). Далее мы выполнили поиск только глаголов shkoj и vij по лемме, чтобы оценить общее число употреблений данных глаголов во всем корпусе. Общее число употреблений глагола shkoj в АНК составляет 17 630, глагола vij - 25862 (всего 43492 словоупотребления). В правой части таблицы показано, какой процент от общего числа употреблений каждого глагола составляют сочетания с изучаемыми предлогами.

Таблица 2. Конструкции с глаголами shkoj/vij и предлогами nё/nga/te(k)

Table 2. Constructions with the verbs shkoj/vij and the prepositions në/nga/te(k)

\begin{tabular}{|c|c|c|c|c|c|}
\hline \multirow[t]{2}{*}{ Предлог } & \multicolumn{3}{|c|}{ Количество } & \multicolumn{2}{|c|}{$\begin{array}{c}\text { \% от общего числа } \\
\text { употреблений shkoj/ vij в АНК }\end{array}$} \\
\hline & shkoj & $v i j$ & Всего & shkoj & $v i j$ \\
\hline$n \ddot{e}$ & 5479 & 4692 & 10171 & $31,08 \%$ & $18,14 \%$ \\
\hline$n g a$ & 270 & 2760 & 3030 & $1,53 \%$ & $10,67 \%$ \\
\hline$t e(k)$ & 929 & 742 & 1671 & $5,26 \%$ & $2,86 \%$ \\
\hline Все три предлога & 6678 & 8194 & 14872 & $37,87 \%$ & $31,67 \%$ \\
\hline
\end{tabular}

Из Таблищь 2 видно, что предлог пё обладает наиболее высокой частотностью в сочетании с глаголами shkoj и vij: контексты с этим предлогом составляют около трети от общего числа употреблений глагола shkoj и более $18 \%$ от общего числа примеров с глаголом vij в АНК. Кроме того, таблица показывает, что суммарно на долю конструкций с предлогами $n g a, n \ddot{e}$ и $t e(k)$ приходится примерно третья часть от общего числа контекстов как с глаголом $\operatorname{shkoj}(37,87 \%)$, так и с глаголом $v i j(31,67 \%)$.

По способу заполнения валентностей цели и источника при глаголе можно выделить следующие типы конструкций: 1) с двумя заполненными валентностями, 2) с одной заполненной валентностью и 3 ) без указания на цель и источник. Для их описания мы использовали терминологию работы Е. В. Рахилиной, где предлагается различать эксплицитное заполнение исходной или конечной точки (конструкцией с предлогом) и анафорическое заполнение, когда начальная или 
конечная точка не выражена в предложении на поверхностном уровне, но известна из предыдущего текста [Рахилина 2008: 318]. К последнему, наряду с заполнением из контекста, мы причисляли также собственно анафору, т. е. случаи, когда дейктические наречия или местоимения (местоимения третьего лица, указательные местоимения) употребляются в типичной для них функции замещения слов и словосочетаний, упомянутых в тексте ранее. Нужно признать, что использование такого признака в корпусном исследовании осложнено тем, что информация может быть в разной степени доступна из предыдущего текста (например, находиться на большом расстоянии от конкретного употребления) и мнение о ее доступности может в некоторой степени определяться компетенциями читателя текста ${ }^{6}$. В этом мы несколько выходим за рамки корпусного подхода. Тем не менее мы считаем, что подобное решение может быть обосновано следующим образом. Во-первых, в большинстве случаев для понимания контекста перемещения при интерпретации примеров нашей выборки нам было достаточно расширить его не более чем на семь предложений в обе стороны (максимальное расширение, допустимое в АНК), что не является большим расстоянием. Во-вторых, мы предполагаем, что автор выбирает средства для описания движения и, как следствие, способ заполнения валентностей при глаголе движения, опираясь на то, что читатель ознакомился с предшествующим текстом.

На первом этапе исследования глаголов shkoj и vij мы проверили предположение о том, что особенности лексической семантики данных глаголов могут отражаться в различном характере поверхностного (синтаксического) оформления аргументов цели и источника. Для этого мы проанализировали по нашим выборкам частотность конструкций с одним или двумя аргументами, а также конструкций, которые не содержат аргументов, указывающих на цель или источник. Далее проверялась гипотеза о том, что изучаемые глаголы могут различаться по способу заполнения валентностей начальной и конечной точек, т. к. указание на тот или иной компонент маршрута может содержаться непосредственно в семантике глагола. Соответственно, нами была предпринята попытка установить, какой способ заполнения является наиболее характерным для каждого из двух глаголов и какая именно валентность, начальной или конечной точки, должна быть заполнена

${ }^{6}$ Мы выражаем благодарность анонимному рецензенту, который обратил внимание на данную проблему. 
в первую очередь. Средства выражения цели и источника и способы оформления соответствующих аргументов при глаголах shkoj и vij мы рассматриваем в подразделе 2.2, а далее, в подразделе 2.3, переходим к обсуждению конструкций с этими глаголами с точки зрения их валентностной структуры.

\section{2. Глаголы shkoj и vij: аргументная структура и семантика}

Вначале мы рассмотрели полученные примеры с точки зрения наличия или отсутствия при глаголе синтаксически выраженных аргументов, обозначающих только источник и/или цель: предложных конструкций со значением объекта-ориентира, к которому (цель) или от которого (источник) движется субъект, дейктических пространственных наречий, существительных или местоимений в дативе. Для всех примеров с синтаксически выраженными аргументами определялось значение предлогов, дейктических наречий и местоимений. Заметим, что аргументы, оформляемые предлогами, были разнообразными с точки зрения семантики и не всегда обозначали компоненты маршрута, ср., например, употребление предлога pas 'после, (вслед) за' для обозначения временно́й последовательности (3).

$\begin{array}{lllll}\text { Erdh-ën } & \text { pas } & \text { nesh } & \text { një } & \text { pjesë } \\ \text { приходить.AOR-AOR.3PL } & \text { PREP } & \text { 1PL.ABL } & \text { один } & \text { часть.NOM.SG.INDF } \\ e & \text { admiratorë-ve } & t e ̈ & \text { Zimerman-it. } \\ \text { F.NOM.SG } & \text { почитатель.PL-GEN.PL } & \text { GEN.PL } & \text { Цимерман-GEN.SG.DEF }\end{array}$

'После нас пришла часть почитателей Цимермана'. [АНК: Ismail Kadare. Hija. 1994]

Такие конструкции, наряду с примерами, где встречались только непространственные аргументы (субъект, объект и др.), мы относили к «безаргументным» ввиду отсутствия аргументов, указывающих на цель или источник. Количественные данные о распределении примеров приводятся в Таблице 3.

Меньше всего - лишь $2 \%$ от общего количества примеров в двух выборках и в каждой отдельно взятой выборке - встретилось примеров с двумя синтаксически выраженными аргументами, которые оформлялись сочетаниями с предлогом (4). В таких конструкциях в целом неоднозначный предлог $n g a$ всегда выполняет функцию маркера источника (как было сказано выше, в албанском языке невозможно 
Таблица 3. Распределение конструкций с глаголами shkoj и vij по способу

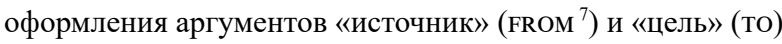

Table 3. Distribution of constructions with the verbs shkoj and vij according to the expression of arguments "source" (FROM) and "target" (TO)

\begin{tabular}{|l|c|c|c|c|c|c|}
\hline \multirow{2}{*}{\multicolumn{1}{|c|}{ Конструкция }} & \multicolumn{2}{|c|}{ shkoj } & \multicolumn{2}{c|}{ vij } & \multicolumn{2}{c|}{ Всего } \\
\cline { 2 - 8 } & Кол-во & \% & Кол-во & \% & \multicolumn{1}{c|}{ Кол-во } & \multicolumn{1}{c|}{} \\
\hline Без аргументов & 35 & $36 \%$ & 20 & $23,8 \%$ & 55 & $30,4 \%$ \\
\hline С одним аргументом & 60 & $62 \%$ & 62 & $73,8 \%$ & 122 & $67,6 \%$ \\
(а) ғвом & 0 & & 16 & & 16 & \\
(б) то & 60 & & 46 & & 106 & \\
\hline С двумя аргументами & 2 & $2 \%$ & 2 & $2,4 \%$ & 4 & $2 \%$ \\
\hline Всего & 97 & $100 \%$ & 84 & $100,0 \%$ & 181 & $100 \%$ \\
\hline
\end{tabular}

кодировать источник иначе). Примеры без аргументов (5) более частотны: их доля во всей выборке составляет 30,4 \%. Более подробный разбор таких конструкций будет приведен далее.

Большинство конструкций (67,6 \% от общего числа примеров) содержали только один синтаксически выраженный аргумент (6). Исходя из этого, можно предположить, что в албанском языке наиболее типичной стратегией является эксплицитное указание только на один компонент маршрута.

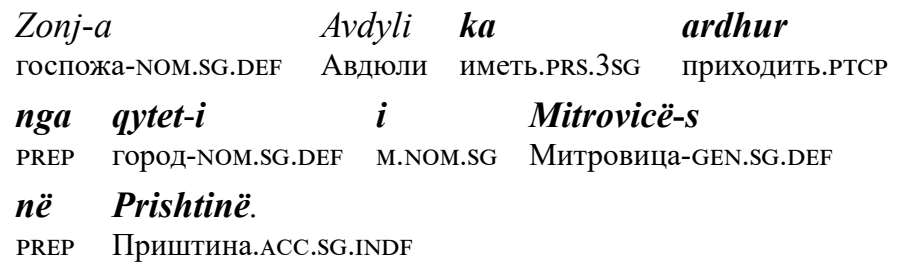

'Госпожа Авдюли приехала из города Митровицы в Приштину'. [AHK: Zёri. 2013]

${ }^{7}$ В ходе первичного анализа примеров возникли затруднения при указании значений предлогов, кодирующих цель и источник. Русский язык использует в соответствующих контекстах большое количество синонимичных предлогов (ср. войти в комнату, взойти на гору; уехать из города, уйти со станции и т. д.), и использование русского в качестве метаязыка в дальнейшем осложнило бы описание албанского материала и выявление закономерностей. По этой причине в качестве метаязыка описания был выбран английский, и основные значения предлогов помечались как FROM (источник) или то (цель). 
Po të dua-sh

nuk shko-jmë, - tha-shë.

COMP SBJV хотеть-SBJV.PRS.2SG NEG идти-PRS.1PL сказать-AOR.1SG 'Если хочешь, мы не поедем, - сказал я'. [АНК: Nasi Lera. Ana Zh. 1995]

\begin{tabular}{|c|c|c|c|c|c|}
\hline Kjo & $n u k$ & do & tho-të & $q \ddot{e}$ & $\ddot{e}$ \\
\hline этоT.F.SG.NOM & NEG & FUT & сказать-PRS.3sc & COMP SB & BJV \\
\hline shko-jmë & atje & me & flamur & $t \ddot{e}$ & bardhë. \\
\hline идти-PRS.1PL & туда & PREP & флаг.ACC.SG.INDF & ACC.SG.INDF & белый \\
\hline
\end{tabular}

Примеры с единственным синтаксическим аргументом, обозначающим цель движения, в случае обоих глаголов оказались более многочисленными, чем примеры с источником. В частности, с vij встретилось 46 подобных конструкций (из 62 примеров с одним аргументом). В выборке с глаголом shkoj полностью отсутствовали примеры с одиночным аргументом, указывающим на источник, хотя в целом такие конструкции обнаруживаются в словарях албанского языка и содержатся в АНК, но не являются частотными. Возможно, таким образом в албанском проявляется общий когнитивный принцип асимметрии начальной и конечной точек движения. Эта близкая к универсальной тенденция к преобладанию цели над источником, называемая «сдвигом в сторону конечной точки» (англ. goal-bias), предполагает, что конечный пункт перемещения выражается эксплицитно чаще, чем начальный. С когнитивной точки зрения это явление может быть объяснено тем, что, поскольку «целью перемещения является достижение нового местоположения субъекта, 〈.. \ именно оно нуждается в наиболее эксплицитном обозначении» [Майсак 2005: 115; o goal-bias см. также Walchli, Zúniga 2006; Beavers et al. 2010; Nikitina 2009, с библиографией].

Как правило, аргументы глаголов shkoj и vij в рассмотренных примерах оформляются с помощью предлогов (7), хотя возможно и указание на компонент маршрута с помощью дативного дополнения со значением адресата действия или сообщения (8), а также дейктического наречия (9). Все контексты, где выражена только начальная точка, относятся к случаям употребления при глаголе vij (16 примеров), и во всех случаях этот аргумент vij оформлялся конструкцией с предлогом nga. В контекстах, где выражен один аргумент со значением цели, или конечной точки движения, предлоги пё и $t e(k)$ оказались самыми частотными маркерами цели как в сочетании с vij, так и с глаголом shkoj. 
Примеров, где конечная точка маркировалась бы предлогом $n g a$, не оказалось ни в одной из выборок, несмотря на то, что такое сочетание возможно: $U=d r e j t u a-n$ nga tribun- $a$ (INACT= направить-AOR.3PL PREP трибуна-NOM.SG.DEF) 'направились к трибуне' [FGjSSh 1980]. Возможно, отсутствие $n g a$ связано, с одной стороны, с небольшим размером выборок, а с другой - с более низкой общей частотностью $n g a^{8}$ в сочетании с изучаемыми глаголами по сравнению с пё и $t e(k)$ (см. Таблииу 2 в подразделе 2.1).
Më 8 shtator
shko-i
nё Prizren.
PREP 8 сентябрь.ACC.SG.INDF идти-AOR.3SG PREP Призрен.ACC.SG.INDF '8 сентября он отправился в Призрен'. [АНК: Historia e popullit shqiptar. Rilindja kombëtare. Vitet 30 të shek. XIX — 1912. 2002]

$\begin{array}{lllll}\text { materiale- } t & q \ddot{e} & \boldsymbol{u}= & \text { shko-jnë } & \text { deputetë-ve } \\ \text { материал.PL-NOM.PL.DEF } & \text { COMP } & \text { 3PL.DAT= } & \text { идти-PRS.3PL } & \text { депутат.PL-DAT.PL } \\ \text { 'материалы, которые поступают депутатам' [AHК: Zёri. 2013] }\end{array}$

$\begin{array}{lllll}\text { Po } & \text { si } & \text { të } & \text { shko-jmë } & \text { atje? } \\ \text { РТСL } & \text { как } & \text { SBJV } & \text { идти-PRS.1PL } & \text { туда }\end{array}$

'Но как же мы пойдем туда?' [АНК: Kim Mehmeti. Vitet e urithit. 2000-2009]

Наблюдения о наличии / отсутствии синтаксически выраженных аргументов при shkoj и vij, как представляется, могут быть интерпретированы с точки зрения семантических свойств этих глаголов, а именно наличия или отсутствия у них ориентированности на цель или источник. При глаголе $s h k o j$, как показано в Таблище 3, преобладают конструкции с эксплицитно выраженной конечной точкой (7), но относительно часто встречаются и употребления без аргументов (см. пример (5) выше). Число примеров этих двух типов составляет 35 и 60 соответственно. Конструкций с эксплицитным обозначением только начальной точки (FROM) в нашей выборке не оказалось, и, как уже было сказано выше, это может косвенно указывать на общую тенденцию к преобладанию конечной точки над начальной точкой маршрута (goal-bias).

В «безаргументном» примере (5) герои обсуждают возможную поездку в Дельфы, однако высказывание, несмотря на то что конечная точка известна из предыдущего контекста, отсылает, по всей видимости, к самой необходимости начинать движение и совершать поездку.

\footnotetext{
${ }^{8}$ Более подробно о конструкциях с предлогом $n g a$ см. в Разделе 3.
} 
В этом контексте конкретные исходный и конечный пункты факультативны, соответственно, они никаким образом не оформляются, и в самом глаголе направление движения также не выражается. Когда при ненаправленном глаголе $s h k o j$ появляется эксплицитное указание на цель, как в примере (7), описываемое движение закономерным образом становится направленным.

Кроме того, интересно то, что в «безаргументных» контекстах глагол shkoj может употребляться в значении «уходить». По-видимому, такое поведение shkoj в албанском языке является следствием тех же «системных» соображений, по выражению Е. В. Рахилиной, в силу которых глагол gо в английском, для создания симметричной пары с come, начинает осмысляться как глагол удаления [Рахилина 2008: 320]. Тем не менее употребление албанского глагола $s h k o j$ в качестве глагола удаления является редким и наблюдается в нашем материале только в конструкциях типа vij e shkoj (приходить.PRS.1SG и идти. PRS.1SG), где shkoj встречается непосредственно в сочетании с глаголом vij и означает «уходить» (3), (10). Контекстов, где shkoj без аргументов «цель» и «источник» употреблялся бы самостоятельно и обозначал удаление, в нашей выборке обнаружено не было. Таким образом, можно сказать, что данный глагол, в терминологии [Майсак 2005], является глаголом «чистого перемещения», который зачастую употребляется без аргументов и не требует при себе эксплицитного указания на тот или иной компонент маршрута.

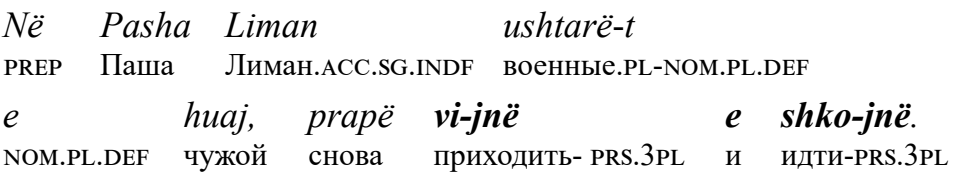

'В заливе Паша-Лиман чужие военные, снова приходят и уходят' [AHK: Rexhep Ferri. Atdheu im torzo. 1997]

В выборке примеров с глаголом vij, так же как и в случае с глаголом shkoj, наблюдается численное преобладание контекстов с одним аргументом (11), (12) по сравнению с контекстами без синтаксически выраженных аргументов (13). Количественные различия здесь более значительны (см. Таблииу 3): число примеров с одним аргументом при $v i j$ в три раза превышает число примеров без аргументов (20 и 62 примера соответственно), в то время как shkoj в нашей выборке употреблялся с одним аргументом в два раза чаще, чем без каких-либо аргументов. В 46 из 84 примеров с vij единственный аргумент обозначает 
цель движения (12) и лишь в 16 из 84 примеров выборки был встречен аргумент со значением источника (11).

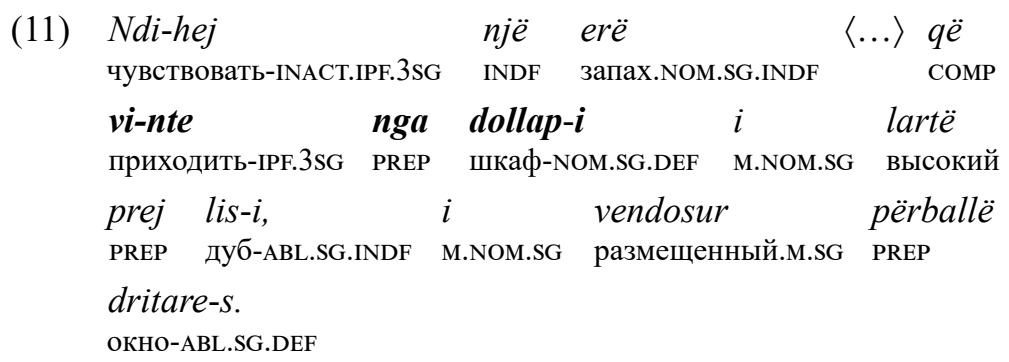

'Чувствовался запах $\langle\ldots\rangle$, который приходил из высокого дубового шкафа, установленного напротив окна'. [АНК: Gustave Flaubert. Zonja Bovari. 2002]

$\begin{array}{llllll}\text { (12) } & \text { krejt } & \text { me } & \text { faj-in } & e & \text { femra-ve } \\ \text { именно } & \text { PREP } & \text { вина-ACC.SG.DEF } & \text { ACC.SG.DEF } & \text { женщина.PL-GEN.PL }\end{array}$

asambleiste që nuk kish-in ardhur

заседательница.UM.PL COMP NEG иметь.IPF-IPF.3PL приходить.PTCP

fare $\boldsymbol{n} \ddot{\boldsymbol{e}}$ seancë

совсем PREP заседание.ACC.SG.INDF

'именно по вине женщин-заседательниц, которые совсем не пришли на заседание' [AHК: Zёri. 2013] (Говорящий здесь - один из депутатов, которые присутствовали на заседании.)

$\begin{array}{lllll}\text { (13) Andaj } & k i s h \text {-te } & k e ̈ r k u a r & n g a & i \\ \text { тогда } & \text { иметь.IPF-IPF.3sG } & \text { просить.PTCP } & \text { PREP } & \text { POSs.3sG }\end{array}$

shoq-i të thërris-te Sheh-un e

мyж-NOM.SG.DEF SBJV звать-IPF.3SG шейX-ACC.SG.DEF ACC.SG.DEF

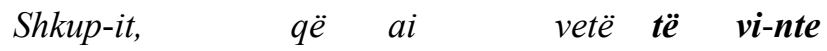

Скопье-GEN.SG.DEF сOMP 3SG.M.NOM сам SBJV приходить-IPF.3sG

e të trego-nte se $c^{\prime}=$ ish-te

и SBJV рассказать-IPF.3SG сомР что $=$ быть.IPF-IPF.3sG

ajo dhembje qe $e=$ mundo-nte

тот.F.NOM.SG боль.NOM.SG.INDF COMP 3sG.ACC= мучать-IPF.3sG

fëmijë-n.

ребенок-ACC.SG.DEF

'Тогда она попросила своего мужа позвать Шейха Скопье, чтобы он сам пришел и рассказал, что за боль мучает ребенка'. [АНК: Kim Mehmeti. Vitet e urithit. 2000-2009] 
Здесь мы видим, что, во-первых, судя по примеру (11), vij может проявлять себя как дейктический глагол, в какой-то мере ориентированный на позицию говорящего и/или наблюдателя. Запах «приходил» из шкафа к тому, кто мог его почувствовать, т. е. конечной точкой этого движения являлся говорящий или тот, кто его замещает (ср. употребление глагола $u д m u$, но не приходить в аналогичных контекстах в русском языке, согласно [Рахилина 2008: 319]: <от иветов> идет приятный заnax). Похожую интерпретацию можно усмотреть в примере (12) рассказ об отсутствующих заседательницах в какой-то мере отсылает нас к позиции того, кто наблюдал за заседанием.

Во-вторых, примечательно, что, в отличие от примеров (5) и (10) с глаголом shkoj, где в отсутствие аргументов глагол приобретает значение «чистого перемещения», в примере (13) с vij, несмотря на отсутствие аргументов, обозначающих исходный и конечный пункты, речь очевидным образом идет о направленном движении. Пример может быть интерпретирован как ситуация прибытия: Шейх из Скопье придет туда, где находятся герой и его дети. Вероятно, это стоит отнести на счет собственной лексической семантики глагола vij и охарактеризовать его как глагол прибытия, ориентированный на конечную точку (goal-oriented).

Таким образом, вышеприведенные количественные данные и проведенный анализ позволяют предположить, что на наличие синтаксически выраженных аргументов, кодирующих цель и источник движения, в некоторой степени влияет семантика изучаемых глаголов. Глагол $v i j$ можно считать ориентированным на конечную точку (goal-oriented, типа английского come). Глагол shkoj в албанском языке не является ориентированным на источник (source-oriented) «глаголом удаления» и, соответственно, не может считаться полноценным «дейктическим антонимом» vij. В сравнении с vij, shkoj демонстрирует более сильную тенденцию к употреблению без указания на компоненты маршрута: доля «безаргументных» контекстов с глаголом shkoj составляет $36 \%$ соответствующей выборки, тогда как в выборке с глаголом $v i j$ конструкции такого типа составляют около $24 \%$. В связи с этим представляется, что албанский глагол shkoj можно отнести к глаголам «чистого перемещения» (типа русского $и \partial т и$ ). 


\section{3. Способы заполнения валентностей «цель» и «источник» при глаголах shkoj и vij}

С точки зрения способа заполнения валентностей глаголов $s h k o j$ и $v i j$, количественное распределение полученных результатов выглядит несколько иначе, так как к числу примеров, которые могут рассматриваться как имеющие две заполненных валентности, относятся не только те контексты, где они заполнены эксплицитно (как в подразделе 2.3), но и те, в которых вторая валентность заполняется анафорически. Распределение проанализированных примеров согласно способу заполнения валентностей представлено в Таблицах 4 и 5.

Таблица 4. Распределение конструкций с глаголом $s h k o j$ по способу заполнения валентностей

Table 4. Distribution of constructions with the verb shkoj by way of filling its valencies

\begin{tabular}{|l|c|c|c|c|}
\hline Источник & Нель заполнена & $\begin{array}{c}\text { Дативное } \\
\text { дополнение }\end{array}$ & $\begin{array}{c}\text { Анафорическое } \\
\text { заполнение }\end{array}$ & Предлог \\
\hline Не заполнена & 34 & 5 & 5 & $\mathbf{4 0}$ \\
\hline $\begin{array}{l}\text { Дативное } \\
\text { дополнение }\end{array}$ & - & - & - & - \\
\hline $\begin{array}{l}\text { Анафорическое } \\
\text { заполнение }\end{array}$ & - & - & 3 & 8 \\
\hline Предлог & - & - & - & 2 \\
\hline
\end{tabular}

Таблица 5. Распределение конструкций с глаголом vij по способу заполнения валентностей

Table 5. Distribution of constructions with the verb vij by way of filling its valencies

\begin{tabular}{|l|c|c|c|c|}
\hline Источник & Не заполнена & $\begin{array}{c}\text { Дативное } \\
\text { дополнение }\end{array}$ & $\begin{array}{c}\text { Анафорическое } \\
\text { заполнение }\end{array}$ & Предлог \\
\hline Не заполнена & 17 & 1 & 22 & $\mathbf{1 8}$ \\
\hline $\begin{array}{l}\text { Дативное } \\
\text { дополнение }\end{array}$ & - & - & - & - \\
\hline $\begin{array}{l}\text { Анафорическое } \\
\text { заполнение }\end{array}$ & - & - & 2 & 7 \\
\hline Предлог & 9 & - & 7 & 1 \\
\hline
\end{tabular}


Общее количество примеров с двумя заполненными тем или иным способом валентностями составляет 13 для глагола shkoj и 17 - для $v i j$ (соответственно, $13,4 \%$ и 20,2\% от общего числа примеров в выборке). В таких контекстах наиболее частотным способом заполнения для обоих глаголов является анафорическое заполнение валентности источника и предложное заполнение валентности цели. Среди таких примеров выделяются собственно анафора, когда источник упоминается в ближайшем контексте (непосредственно в том же или в предыдущем предложении) и кодируется при исследуемом глаголе, например, дейктическим наречием (14), и случаи, когда источник известен из дальнего контекста или же непосредственно из познаний читателя (15a) либо в этом контексте не указан, поскольку эта информация, по мнению автора текста, несущественна для читателя (15б).

$\begin{array}{lllll}\text { Do } & t \ddot{e} & \text { merr-nin } & k e ̈ s h t j e l l e ̈-n & e \\ \text { FUT } & \text { SBJv } & \text { брать-IPF.3PL } & \text { крепость-ACC.SG.DEF } & \text { ACC.SG.DEF }\end{array}$

Shkodr-ës $\quad e$ prej andej do të shko-nin Шкодра-GEN.SG.DEF и PREP оттуда FUT SBJV идти-IPF.3PL

drejt Sofje-s.

PREP София-ABL.SG.DEF

'Они возьмут крепость Шкодры и оттуда пойдут в направлении Софии'. [АНК: Historia e popullit shqiptar. Shqipëria nën Perandorinë Osmane gjatë shek. XVI — vitet 20 të shek. XIX. 2002]

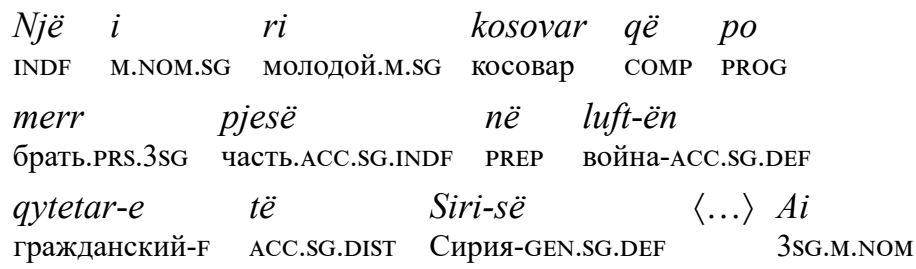

mes tjera-sh tho-të se $\boldsymbol{k a}$

PREP другой.F.PL-ABL2 сказать-PRS.3SG COMP иметь.PRS.3SG

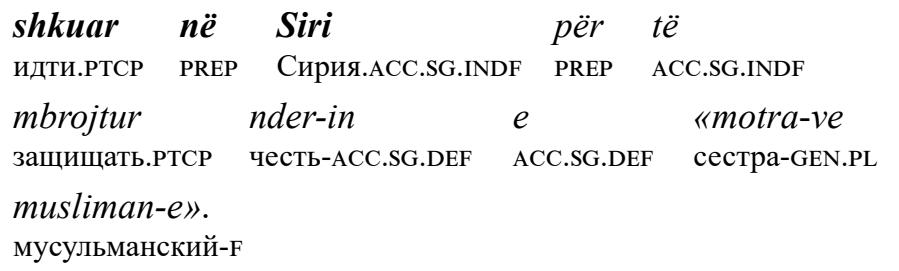


'Молодой косовар, который принимает участие в гражданской войне в Сирии $\langle\ldots\rangle$. Он среди прочего говорит, что поехал в Сирию, чтобы защищать честь мусульманских сестер'. [АНК: Zёri. 2013]

(156) Kish-te

\section{ardhur në Amerikë}

иметь.IPF-IPF.3SG приходить.PTCP PREP Америка.ACC.SG.INDF

$\begin{array}{llllll}p \ddot{e} r & t \ddot{e} & d y t \ddot{e}-n & h e r e ̈ & m \ddot{e} & 1920 . \\ \text { PREP } & \text { ACC.SG.DIST } & \text { вTорой-ACC.SG.DEF } & \text { pa3.UM.SG } & \text { PREP } & 1920\end{array}$

'Он приехал в Америку второй раз в 1920 году'. [АНК: Ilir Ikonomi. Faik Konica. Jeta në Uashington. 2011] (Из контекста известно, что герой - албанец, который работает в итальянском консульстве в Нью-Йорке. Откуда именно он прибыл, не указано, несмотря на то, что жанр биографии, к которому принадлежит данный текст, предполагает фактографическую точность).

Особый интерес представляют случаи, когда одна из валентностей не заполнена. Таких контекстов одинаковое количество при обоих глаголах (50 примеров из 97 с shkoj и из $84-$ с vij). Преобладают примеры с одной заполненной валентностью цели (все 50 примеров с глаголом shkoj и 41 пример из $50-\mathrm{c} v i j)$, которая чаще всего заполняется сочетанием с предлогом. Данные наблюдения в целом соответствуют результатам, полученным при подсчете конструкций с синтаксически выраженными аргументами в подразделе 2.2.

Оба глагола демонстрируют тенденцию к заполнению валентности цели предложной конструкцией при незаполненной валентности источника (при $v i j$ доля таких конструкций составляет $21 \%$, а при глаголе $s h k o j-41 \%$ ). Анафорическое заполнение валентности цели при незаполненной валентности источника (16) более характерно для глагола vij (доля такого рода употреблений составляет $26 \%$, или 31 пример из 84), чем для $\operatorname{shkoj}(5 \%$, или 8 примеров из 97). Вероятно, это связано с тем, что vij дейктически ориентирован на говорящего или на иного значимого участника ситуации, как в примере (13) выше, и на конечную точку легко указать, исходя из его положения. И если в ситуации прибытия конечная точка уже определяется как позиция говорящего / наблюдателя, то исходя из этого можно определить и начальную точку как некоторый пункт, не совпадающий с этой позицией [Рахилина 2008: 319]. Более точное определение начального пункта при этом не всегда возможно: информация о нем может полностью отсутствовать в тексте, будучи известной автору и несущественной для 
читателя, как показывает пример (15a), либо быть неважной в принципе, как в примере (15б).

Заполнение валентности цели с помощью дативного дополнения (при незаполненном источнике) при глаголе $v i j$ встречается реже, чем при shkoj (1 и 5 примеров соответственно). Во всех случаях это непространственные конструкции, в которых дополнение, выраженное существительным в дативе и дублируемое местоименной клитикой, обозначает реципиента / адресата (16), (17).

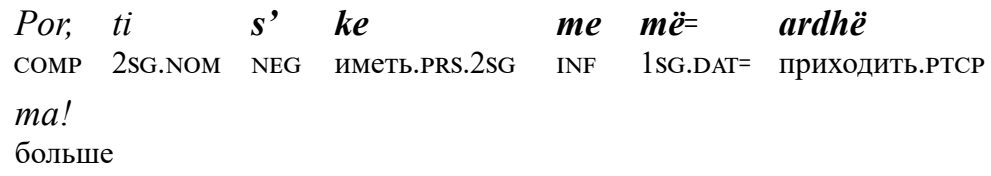

'Но ты ко мне больше не придешь!' [АНК: Rushit Ramabaja, Rrëmbimi i vajzës së këngës. 2001]

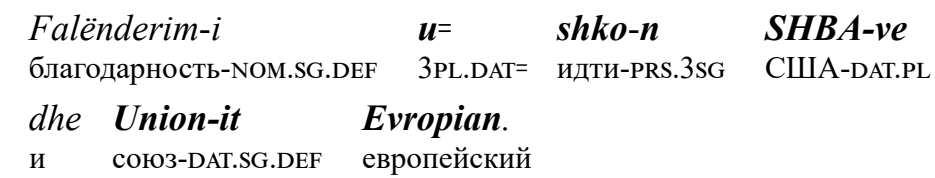

'Благодарность отправляется [букв. «идет»] США и Европейскому союзу'. [АНК: Koha.mk. 2012]

В целом, можно заметить, что даже с учетом анафорического заполнения валентностей при обоих глаголах (чего не делалось в подразделе 2.2) случаев, когда валентность цели, или конечной точки оставалась бы незаполненной, меньше, чем тех, где не выражен источник, или исходная точка. При глаголе shkoj валентность исходной точки не заполняется в 84 случаях из 97 (примерно $87 \%$ от общего числа примеров), а при $v i j-$ в 58 из 84 (примерно $69 \%$ ). Валентность конечной точки оказывается незаполненной только в 26 примерах (30\%) с глаголом vij, а с shkoj таких примеров 34 (35\%). В случае с глаголом vij можно предположить, что аргумент «источник» не является существенным в плане выражения идеи прибытия, которая, как мы упоминали выше, заложена в семантике глагола. Большое же количество примеров, содержащих эксплицитное указание на цель, но не описывающих источник, при глаголе «чистого перемещения» shkoj может указывать на то, что в албанском языке реализуется общий когнитивный принцип ориентации на цель движения (goal-bias). 


\section{3. Глаголы shkoj и vij в конструкциях с предлогом nga}

Полезным диагностическим контекстом для изучения свойств глаголов shkoj и vij стали конструкции с предлогом $n g a$ 'от, из; в, к', который способен кодировать как цель, так и источник. Мы предположили, что выбор значения предлога $n g a$ зависит от того, в каком порядке заполняются валентности цели и источника при глаголе (и, соответственно, от контекста и в какой-то степени от свойств самого глагола), а значит, распределение употреблений $n g a$ в разных значениях в итоге будет следовать закономерностям, описанным в 2.3. Чтобы проверить это предположение, мы дополнительно собрали и проанализировали две выборки из 238 конструкций с глаголом shkoj и предлогом $n g a$, а также 90 конструкций вида «vij $+n g a{ }^{9}$.

Как было показано во Введении, в семантике глаголов движения типа соте и go присутствует дейктический компонент, и при указании на исходный или конечный пункты определенную роль может играть позиция участников ситуации. В связи с этим мы использовали в анализе некоторые элементы дейктического подхода и классифицировали полученные примеры по типу дискурса, разделяя их на примеры диалога и нарратива. При этом мы опирались на исследования Е. В. Падучевой и Ю. Д. Апресяна на материале русского языка. Описание движения связано с определенными ориентирами, которые в контексте речевой ситуации зачастую зависят от положения ее участников, что подводит нас к понятию говорящего и коммуникативной ситуации. Нормальная коммуникативная ситуация - это, как правило, диалог двух людей, один из которых, говорящий, сообщает некую информацию своему собеседнику - слушающему. Относительно говорящего и его восприятия организуется пространство в высказывании. Используя терминологию Дж. Лайонза, Е. В. Падучева в своей работе называет такую ситуацию канонической, отмечая, что именно здесь наблюдается нормальное функционирование языка [Падучева 2010: 259], но предлагает различать различные режимы интерпретации дейктических элементов: речевой, или диалогический, (первичный дейксис в терминах Ю. Д. Апресяна), нарративный и синтаксический [Падучева 2010: 265]. Так, согласно этой классификации, любой разговор, даже если он

\footnotetext{
9 Количество примеров указано за вычетом «шума».
} 
не вполне соответствует условиям каноничности (например, разговор по телефону, когда говорящий и слушающий находятся в разных местах), считается примером диалогического режима, так как здесь все равно присутствует реальный говорящий. В нарративном режиме, напротив, не может быть полноценной фигуры говорящего за отсутствием канонической речевой ситуации [Падучева 2010: 265]. В нарративе, где говорящий отсутствует либо выступает как объект наблюдения, субъектом, относительно которого ориентирована описываемая ситуация в пространстве, является другое лицо - наблюдатель, референциально не совпадающий с говорящим [Апресян 1986/1997: 277-278].

Кроме того, при анализе примеров учитывались параметры, упомянутые в Разделе 2: способ оформления аргументов, значение предлога и тип употребления. Преимущественное внимание в этой части исследования уделялось пространственным конструкциям с предлогом nga (116 из 238 примеров с глаголом shkoj и 30 из 90 - с глаголом vij). В Таблицах 6 и 7 отражено распределение конструкций по указанным параметрам.

Таблица 6. Распределение пространственных употреблений $n g a$ при глаголе shkoj 'идти' по способу оформления аргументов «источник» (FROм) и «цель» (то), значению предлога и режиму интерпретации

Table 6. Distribution of spatial usages of $n g a$ with the verb shkoj 'go', based on the way of expression of the arguments "source" (FROM) and "goal" (TO), the meaning of the preposition, and the mode of interpretation

\begin{tabular}{|c|c|c|c|c|}
\hline \multirow[t]{2}{*}{ Конструкция } & \multirow[t]{2}{*}{ Значение nga } & \multicolumn{2}{|c|}{$\begin{array}{c}\text { Режим } \\
\text { интерпретации }\end{array}$} & \multirow[t]{2}{*}{ Всего } \\
\hline & & Диал. & Happ. & \\
\hline \multirow{4}{*}{ С одним аргументом } & то & 18 & 25 & 43 \\
\hline & FROM & 2 & 14 & 16 \\
\hline & FROM / TO (c vij e shkoj) & 0 & 4 & 4 \\
\hline & VIA & 1 & 0 & 1 \\
\hline $\begin{array}{l}\text { С двумя аргументами } \\
\text { ('from... to') }\end{array}$ & FROM & 0 & 52 & 52 \\
\hline & & 21 & 95 & 116 \\
\hline
\end{tabular}

Около половины примеров (52 употребления из 116) составляют конструкции с выражением пространственного предела, где обе валентности глагола shkoj заполнены словосочетаниями с предлогами

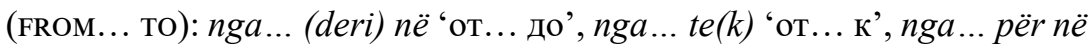


'от... в'. В таких случаях $n g a$ всегда кодирует отправную точку. Примеры, в которых на поверхностном уровне (сочетанием с предлогом $n g a$ в пространственном значении) выражен только один аргумент, составляют 64 из 116 контекстов, представленных в нашей выборке. В 43 из 64 примеров предлог употреблен в значении то (цель) и только в 16 - в значении FROM (источник). Один из 64 примеров с одним аргументом содержит предлог $n g a$ в значении, которое можно охарактеризовать как 'VIA' (18). В четырех примерах предложная группа с $n g a$ является единственным аргументом конструкции vij e shkoj 'приходить и уходить' (19) ${ }^{10}$.

\begin{tabular}{|c|c|c|c|c|c|}
\hline $\begin{array}{l}\text { sikur } \\
\text { COMP }\end{array}$ & $\begin{array}{l}t \ddot{e} \\
\text { SBJV }\end{array}$ & $\begin{array}{l}n a= \\
\text { 1PL.DAT }=\end{array}$ & $\begin{array}{l}d u \text {-hej } \\
\text { хотеть.INACT-INACT.IPF.3SG }\end{array}$ & $\begin{array}{l}t \ddot{e} \\
\text { SBJV }\end{array}$ & $\begin{array}{l}\text { shko-nim } \\
\text { идти-IPF.1PL }\end{array}$ \\
\hline 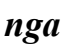 & Qafë & & an-a & & \\
\hline $\mathrm{PRE}$ & перев & ил.UM.SG.I & Сан-NOM.SG.DEF & & \\
\hline
\end{tabular}

'если бы нам пришлось проходить через перевал Сан' [АНК: Zёri. 2013] (Речь идет о дороге, которая проходит в удачно расположенном месте.)

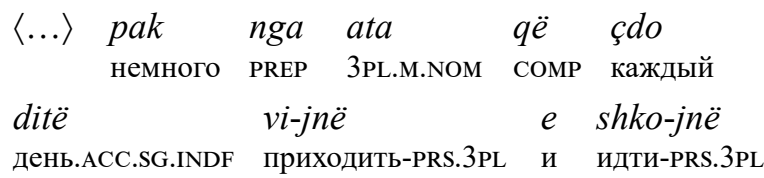

nga kryeqendr-a ta $=\quad$ hedh-in

PREP столица-NOM.SG.DEF SBJV:3SG.ACC $=$ кидать-PRS.3PL

një sy $\quad$ një frymë andej

INDF глаз.ACC.SG.INDF и INDF вздох.ACC.SG.INDF туда

‘ $\langle.$.$\rangle немногие из тех, кто каждый день приезжает и уезжает$ из столицы, чтобы заглянуть туда [В музей. $-K . K$.]' [АНК: Zëri. 2013]

В русском языке глаголы приходить/приезжать и уходить / уезжать имеют разное предложное управление, и в высказываниях типа

\footnotetext{
${ }^{10}$ Порядок глаголов в конструкции может быть другим (shkoj e vij 'уходить и приходить'), и в таких случаях она чаще употребляется без предложных аргументов, либо с предлогом nё, кодирующим цель: shko-jnë e vi-jnë në Tiranë (приходить-PRS.3PL и идти-PRS.3PL PREP Тирана-ACC.SG.DEF) 'уезжают и приезжают в Тирану' [АНК: Panorama. 2016]. Примеров с $n g a$ обнаружено не было, поэтому конструкции с таким порядком глаголов здесь не рассматриваются.
} 
(19) с помощью предлога из кодируется только источник движения при последнем. В албанском языке оба соответствующих глагола глагол прибытия vij и глагол shkoj, который в данном контексте функционирует как глагол удаления, - могут управлять конструкцией c nga. Значение предлога при этом зависит, как показано выше, от способа заполнения валентностей начальной и конечной точек маршрута и, вероятно, в какой-то мере от типа дискурса и позиции в ситуации говорящего или наблюдателя. В частности, в примере (19) столица, где находится наблюдатель, является и конечной точкой маршрута, по которому наблюдаемые субъекты прибывают (vijnë), и начальной точкой траектории, по которой они удаляются (shkojnë). Можно сказать, что конструкция с предлогом $n g a$, способным выражать оба значения, заполняет соответствующие валентности и у глагола $v i j$, и у глагола $s h k o j$.

Количественные данные об употреблении конструкций с одним аргументом при shkoj в разных типах дискурса показывают, что в диалогическом режиме преобладают примеры, в которых предлог $n g a$ принимает значение то (18 из 21 примера, т. е. примерно $86 \%$ ), то есть в нормальной диалогической ситуации $n g a$ при глаголе shkoj скорее проявляет тенденцию к кодированию цели. В нарративном режиме контексты с оформлением цели с помощью $n g a$ также оказываются несколько частотнее, чем контексты, где этот предлог кодирует источник, и составляют больше половины всех случаев (25 из 43 примеров, или 58 \%). Таким образом, в нарративном режиме также можно усмотреть тенденцию к кодированию цели при глаголе shkoj с помощью конструкции с $n g a$, которая, тем не менее, ярче проявляется в диалогической ситуации, где пространственные отношения между говорящим и слушающим могут быть визуально оценены (см. Таблицу 7, с. 151).

При глаголе $v i j$ предлог $n g a$ в подавляющем большинстве примеров выборки - как в диалогическом, так и в нарративном режиме - употребляется в значении FROM (источник). Значение то почти не встречается (всего один пример). Помимо этого, нужно отметить, что в нашей выборке встретилось существенно меньше примеров с двумя синтаксически выраженными аргументами, чем примеров с одним аргументом, выраженным конструкцией с $n g a$ (3 и 26 соответственно). В трех примерах с двумя аргументами, попавших в выборку с глаголом vij, «источник» и «цель» оформляются предложными конструкциями (20); как можно заметить, в этом отношении vij сильно отличается от глагола shkoj. 
Таблица 7. Распределение пространственных употреблений $n g a$ при глаголе vij ‘приходить’ по способу оформления аргументов «источник» (FROM) и «цель» (то), значению предлога и режиму интерпретации

Table 7. Distribution of spatial usages of $n g a$ with the verb vij 'come', based on the way of expression of the arguments "source" (FROM) and "goal" (TO), the meaning of the preposition, and the mode of interpretation

\begin{tabular}{|c|c|c|c|c|}
\hline \multirow[t]{2}{*}{ Конструкция } & \multirow[t]{2}{*}{ Значение nga } & \multicolumn{2}{|c|}{$\begin{array}{c}\text { Режим } \\
\text { интерпретации }\end{array}$} & \multirow[t]{2}{*}{ Всего } \\
\hline & & Диал. & Happ. & \\
\hline \multirow[t]{3}{*}{ С одним аргументом } & TO & 1 & 0 & 1 \\
\hline & FROM & 0 & 26 & 26 \\
\hline & FROM / TO (c vij e shkoj) & 0 & 4 & 4 \\
\hline $\begin{array}{l}\text { С двумя аргументами } \\
\text { (FROM... TO) }\end{array}$ & FROM & 0 & 3 & 3 \\
\hline & & 1 & 33 & 34 \\
\hline
\end{tabular}

\section{(20) flamur-i} флаг-NOM.SG.DEF

$$
q \ddot{e} \quad \text { erdh }-i
$$

dje

nga

UEFA

COMP

\section{nё adresë}

$t \ddot{e}$

Federatë-s

Shqiptar-e

PREP адрес.ACC.SG.INDF ACC.SG.INDF Федерация-GEN.SG.DEF албанский-F

'флаг, который прибыл вчера из УЕФА на адрес албанской Федерации’ [АНК: Gazeta Shqiptare. 2006]

Можно отметить, что, в сущности, уже на этапе анализа количественных данных гипотеза о том, что выбор значения предлога может зависеть от способа заполнения валентностей цели и источника при глаголе, находит некоторое подтверждение. В составе конструкций с двумя эксплицитно заполненными валентностями предлог $n g a$ выступает в четко определенном значении: выражается значение источника, т. к. в албанском языке практически невозможно кодировать источник иначе (как было указано в подразделе 2.1, альтернативой $n g a$ является менее частотный предлог рrеј 'из, от'), а использование предложных групп, включающих в себя два предлога $n g a$, невозможно [АНК].

То же справедливо и для случаев, когда эксплицитно (конструкцией с предлогом $n g a$ ) заполнена только одна валентность глагола, а вторая становится известной из контекста. В примере (21) используется глагол shkoj, который, как мы определили в 2.2, является глаголом «чистого перемещения». Это означает, что обе валентности данного 
глагола - цели и источника - факультативны и могут не заполняться, в отличие от ориентированного на цель движения vij. Из этого же предложения, которое является, в терминах Е. В. Падучевой, примером неканонической коммуникативной ситуации - нарратива с повествователем, замещающим «канонического» говорящего / наблюдателя, становится известно, что Нести в конечном итоге оказывается в Тиране (Албания). Наличие этой информации, по-видимому, «заставляет» $n g a$ играть роль маркера исходной точки при shkoj.

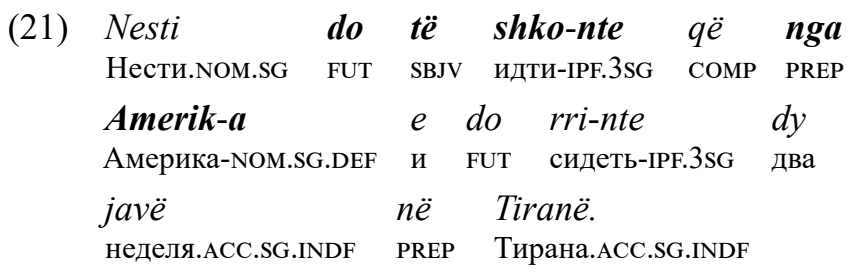

'Нести поедет аж из Америки и проведет две недели в Тиране'. [AHK: Pëllumb Kulla. Rrëfenja nga Amerika. 2003]

Выбор глагола в (21), вероятно, обусловлен дейктическими характеристиками текста. Было бы закономерно употребить глагол vij, который содержит в своей семантике идею прибытия и является дейктическим, если бы наблюдатель (повествователь) находился в Тиране и там ждал прибытия героя из Америки. Однако местоположение наблюдателя неопределенно (и, по всей видимости, это не Тирана), а значит, vij не вполне подходит и нужно использовать shkoj для описания данной ситуации движения.

Аналогичным образом можно интерпретировать и примеры (22) и (23), где не вполне очевидно, совершалось ли движение по направлению к востоку (22)/ к северу (23) или же, наоборот, эти стороны света являлись пунктом отправления. Поскольку предлог $n g a$ способен оформлять как начальную, так и конечную точку маршрута, и то и другое вполне вероятно. В обоих примерах глаголу shkoj предпочитается глагол $v i j$, который является глаголом, ориентированным на конечную точку (goal-oriented). Неизвестным компонентом маршрута, на который указывает предложный аргумент глагола, в этом случае должен быть источник. С учетом этого факта примерам (22) и (23) можно дать вполне однозначную интерпретацию («с востока», «с севера»).

Действительно, при изучении предшествующего контекста в первом случае (22) становится ясно, что речь идет о захвате Крита турками, которые напали не с востока, а с запада («если бы турки пришли 
с востока» - контрафактическое условие, которое не было выполнено). Во втором случае (23) из предшествующего контекста трудно установить, как живущий в Македонии рассказчик, который является наблюдателем, расположен по отношению к прибытию птиц. Но в следующем за этим предложении указано, что они прибыли со стороны Косова, т. е. с севера.

\begin{tabular}{|c|c|c|c|}
\hline$n \ddot{e}$ & $q o-f t \ddot{e}$ & se & turq-it \\
\hline PREP & быть.OPT-OPT.PRS.3SG & COMP & турок.PL-NOM.PL.DEF \\
\hline & i-nin & nga & lindj-a \\
\hline
\end{tabular}

'если бы турки пришли с востока' [АНК: Ben Blushi. Tё jetosh në ishull. 2008]

$\begin{array}{llll}\langle\ldots\rangle \text { plima } & t \ddot{e} & \text { dendur- } a & t \ddot{e} \\ \text { стая.NOM.PL.INDF } & \text { INDF.PL } & \text { густой-F.PL } & \text { PL.INDF }\end{array}$

korba-ve që vi-nin nga veri-u.

ворона.PL-GEN.PL REL приходить-IPF.3SG PREP север-NOM.SG.DEF

$V$ i-nin atje nga ${ }^{11}$ pasmale-t

приходить-IPF.3SG туда PREP загорье.PL-NOM.PL.DEF

ku shtri-hej Kosov-a.

где простирать-INACT.IPF.3SG Косово-NOM.SG.DEF

'〈...〉 плотные стаи ворон, которые прибывали с севера. Они прибывали туда из-за гор [досл. «из загорья»], где простиралось Косово'. [АНК: Kim Mehmeti. Fshati pa varreza. 2002]

Если нет необходимости указывать источник (что особенно типично для контекстов с глаголом shkoj), то, возможно, нет и ограничений для выбора предлога при заполнении валентности цели, и нередко таким предлогом становится nga. Это предположение подтверждается примерами с shkoj в диалогическом режиме интерпретации (24), (25), где сочетанием с $n g a$ заполнена только одна валентность глагола, а именно валентность цели.

\section{(24) Shko nesër nga babazot-i. \\ ходить.IMP.2SG завтра PREP дедушка-NOM.SG.DEF \\ ‘Пойди завтра к дедушке’. [АНК: Ismail Kadare. Kronikë në gur. 1963]}

11 Здесь предлог имеет ясное значение «из», т. к. валентность цели заполняется дейктическим наречием atje 'туда', отсылающим к месту, где находится наблюдающий за воронами персонаж. 


\section{(25) $M \ddot{e}=$ tha-në se ke shkuar \\ 1SG.DAT $=$ сказать.AOR-AOR.3PL COMP иметь.PRS.2SG ходить.PTCP \\ nga pyje-t. \\ PREP леC.PL-NOM.PL.DEF \\ 'Мне сказали, что ты ходил в леса'. [АНК: Dritëro Agolli. Trënd- afili në gotë. 1979]}

В примере (24) мы видим каноническую ситуацию общения, в которой говорящий и слушающий находятся в одной точке. Валентность начальной точки, таким образом, заполнена дейктически (она определяется позицией говорящего), а на конечную точку указывает конструкция с предлогом ${ }^{12}$.

В примере (25) некоторые люди могли наблюдать героя выходящим из леса либо входящим в него (обе ситуации в албанском языке могут быть описаны конструкцией с $n g a$ ), но мы можем полагать, что $n g a$ ведет себя так же, как в (24), где собеседники находились в одной точке, и обозначает цель. Хотя в (25) не содержится никаких пояснений на этот счет ${ }^{13}, n g a$ вполне естественно воспринимается как маркер цели. По всей видимости, определенную роль здесь играет, с одной стороны, тенденция к преобладанию конечной точки над начальной (goal-bias) и, соответственно, эксплицитному выражению цели, а с другой — то, что глагол shkoj не имеет ориентации на определенную точку маршрута. Вероятно, имеет значение и то, что для движущегося субъекта целью было посещение леса; в результате именно валентность цели при shkoj оказывается заполненной конструкцией с $n g a$.

К диалогическому режиму относится и единственный пример в нашей выборке, в котором употребляется глагол $v i j$ и одна из валентностей глагола оказывается эксплицитно заполненной предлогом $n g a$ в значении цели (26).

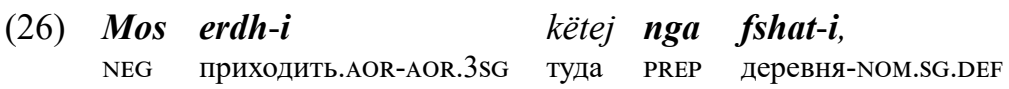

12 При этом объект-ориентир «дом», который очевидным образом является конечной точкой движения героя, подменяется его обладателем (в дом дедушки = к дедушке). Дедушка здесь выступает в качестве т. н. локативного посессора [Даниэль 2001: 224; Ганенков 2002: 21].

13 Информация о том, что речь идет именно о походе в лес обнаруживается очень далеко в предшествующем контексте: герой (писатель) посещает там могилы партизан, т. к. пишет текст о войне. 
xhaxha?

дядя.NOM.SG.INDF

'Он не приходил туда, в деревню, дядя?' [АНК: Jakov Xoxa. Lumi i vdekur. 1967]

Здесь говорящий рассказывает о событиях, произошедших в албанском городе Фиер перед приходом партизан, и спрашивает своего собеседника («дядя») о судьбе третьего лица. Беседа происходит в Фиере, о чем можно узнать из предшествующего контекста, и говорящий интересуется, не заходил ли этот человек в деревню, о которой известно собеседнику. Необходимость эксплицитного кодирования цели при глаголе $v i j$ в данном случае обусловлена тем, что оба участника сейчас находятся не в селе. Если бы они были там, необходимую информацию о цели можно было бы извлечь из их непосредственного местонахождения и семантики глагола. Можно сказать, что здесь отчасти подтверждается предположение о том, что в диалогическом режиме наиболее ярко проявляется общая тенденция к маркированию цели, а не источника при глаголах движения (goal-bias). Вместе с тем, именно расположение говорящего и слушающего, которое в примере (27) принимается за точку отсчета, является первичным фактором для выбора предлога и способа заполнения валентностей при глаголе vij, который в большинстве случаев ведет себя как типичный глагол прибытия.

\section{4. Заключение}

По результатам нашего исследования лексической семантики двух основных глаголов движения в албанском языке, shkoj 'идти' и vij ‘приходить', и анализа особенностей кодирования цели и источника при данных глаголах, который проводился с преимущественным вниманием к предложному заполнению этих валентностей, мы можем сформулировать следующие выводы:

1) Основными предлогами, кодирующими конечную точку маршрута, являются $n \ddot{e}$ и $t e(k)$. Предлог $n g a$ может оформлять как начальную, так и конечную точки маршрута, проявляя склонность к неоднозначности в кодировании цели и источника (source-goal ambiguity), за исключением контекстов, в которых обе валентности заполняются предложными конструкциями и $n g a$ с необходимостью кодирует источник. 
2) В результате анализа двух случайных выборок, включающих конструкции с различным оформлением аргументов и разными способами заполнения валентностей при глаголах shkoj и vij, было замечено, что в албанском языке наблюдается тенденция к эксплицитному заполнению валентности цели (goal-bias), средства оформления которой в албанском более разнообразны и многочисленны, чем средства для обозначения источника. При этом чаще всего на валентность цели указывают предлоги. Аналогичные наблюдения были сделаны на материале дополнительных выборок с предлогом $n g a$, способным кодировать и цель и источник.

3) Характер заполнения валентностей цели и источника при глаголах shkoj и vij определяется семантикой глагола. В случайных выборках (в особенности в примерах без аргументов), а также в дополнительных выборках примеров с предлогом $n g a$, было видно, что глагол $v i j$ содержит в своем значении указание на движение в сторону определенной точки и, таким образом, может быть охарактеризован как глагол прибытия, или глагол, ориентированный на конечную точку (goaloriented). Глагол shkoj, в отличие от vij, может употребляться как глагол ненаправленного перемещения (ходить). Этот глагол редко встречается в значении глагола удаления, ориентированного на начальную точку (source-oriented), и не может считаться «дейктическим антонимом» vij. Судя по примерам случайной выборки, при shkoj часто не кодируется ни одна из валентностей, либо кодируется одна из двух с примерно одинаковой частотой, что позволяет считать этот албанский глагол глаголом «чистого перемещения». Таким образом, он типологически более близок к русскому глаголу идтu, чем к английскому go, представляющему собой глагол удаления [Майсак 2005; Рахилина 2008].

4) Анализ примеров с глаголами shkoj и vij в сочетании с $n g a$ с учетом режима интерпретации показал, что тенденция к кодированию цели (goal-bias) ярче всего проявляется при глаголе «чистого перемещения» $s h k o j$ в нормальной коммуникативной ситуации («диалогический режим»), когда положение говорящего и/или наблюдателя известно и пространственные отношения между объектами могут быть визуально оценены. В нарративном режиме предлог $n g a$ при обоих глаголах, как правило, указывает на источник.

Дальнейшее исследование с расширением списка глаголов и с использованием не только корпусных, но и экспериментальных методов позволит углубить наши знания о том, какие факторы (семантика глагола, семантика предлога, тип объекта в предложной конструкции и др.) 
определяют способ заполнения валентностей «цель» и «источник» при глаголе в целом и выбор той или иной конструкции при предложном заполнении, в частности.

\section{Список условных сокращений}

1, 2, 3 - лицо глаголов и местоимений, ABL - аблатив, АCC - аккузатив, AOR - аорист, COMP — комплементайзер, GEN — генитив, DAT — датив, DEF — показатель определенной формы, DIST - дистантная позиция артикля, F - женский род, FUT - будущее время, INACT - показатель неактивного залога, INDF — показатель неопределенной формы, IMP - императив, IPF — имперфект, м - мужской род, NEG - показатель отрицания, NOM - номинатив, PL - множественное число, PROG - прогрессив, PRS - настоящее время, РTCP — причастие, PREP - предлог, REL - показатель релятивизации, SBJV - конъюнктив, SG - единственное число, $\mathrm{UM}$ - немаркированный падеж.

\section{Литература}

Апресян 1986/1997 - Ю. Д. Апресян. Дейксис в лексике и грамматике и наивная модель мира // Семиотика и информатика: Opera selecta. М.: Русские словари, 1997. Вып. 35. С. 272-298. (Впервые опубликовано в: Семиотика и информатика. 1986. Вып. 28. С. 5-33).

Ганенков 2002 - Д. С. Ганенков. Модели полисемии пространственных показателей. Дипломная работа. М.: МГУ, 2002.

Даниэль 2001 - М. А. Даниэль. Падеж и локализация // А. Е. Кибрик (ред.). Багвалинский язык. Грамматика. Тексты. Словари. М.: Наследие, 2001. С. 203-230. Жугра 1986 - А. В. Жугра. Аспектуальное значение конструкций с глаголом vij 'приходить' в албанском языке // А. В. Десницкая (отв. ред.). Вопросы языка и литературы народов балканских стран. Л.: Изд-во ЛГУ, 1986. С. 54-61.

Клименок 2018 - К. С. Клименок. Пространственный дейксис в конструкциях с предлогом $n g a$ в литературном албанском языке: корпусное исследование. Курсовая работа. СПб.: СПбГУ, 2018.

Левонтина, Шмелев 2005 - И. Б. Левонтина, А. Д. Шмелев. На своих двоих: лексика пешего перемещения в русском языке // А. А. Зализняк, И. Б. Левонтина, А. Д. Шмелев. Ключевые идеи русской языковой картины мира. М.: Языки славянской культуры, 2005. С. 76-96.

Майсак 2005 - Т. А. Майсак. Типология грамматикализации конструкции с глаголами движения и глаголами позиции. М.: Языки славянских культур, 2005.

Падучева 2010 - Е. В. Падучева. Семантические исследования: Семантика времени и вида в русском языке. Семантика нарратива. 2-е изд., испр. и доп. М: Языки славянской культуры, 2010. 
Рахилина 2008 - Е. В. Рахилина. Когнитивный анализ предметных имен. М.: Русские словари, 2008.

Beavers et al. 2010 - J. Beavers, B. Levin, S. W. Tham. The typology of motion expressions revisited // Journal of Linguistics. 2010. № 46 (3). P. 331-377. DOI: 10.1017/ S0022226709990272.

Nikitina 2009 - T. Nikitina. Subcategorization pattern and lexical meaning of motion verbs: a study of the source/goal ambiguity // Linguistics. 2009. № 47 (5). P. 1113-1141.

Fillmore 1971/1983 — C. J. Fillmore. How to know whether you're coming or going // G. Rauh (ed.). Essays on deixis. Tübingen: Narr, 1983. Р. 219-227. (Впервые опубликовано в: K. Hyldgard-Jensen (ed.). Linguistik. Frankfurt a. M.: Athenäum Verlag, 1971. P. 369-379).

Walchli, Zúñiga 2006 - B. Walchli, F. Zúñiga. Source-Goal (in)difference and the typology of motion events in the clause // Sprachtypologie und Universalienforschhung. 2006. № 59 (3). P. 284-303.

\section{Источники}

АНК 2016 - М. С. Морозова, А. Ю. Русаков, Т. А. Архангельский. Албанский национальный корпус (версия 2011-2016 гг.) (электронный ресурс). URL: http:// web-corpora.net/AlbanianCorpus (дата обращения: 09.05.2019).

FGjSSh 1980 - A. Kostallari (kryered.). Fjalori i gjuhës së sotme shqipe: me rreth 41.000 fjalë. Tiranë: Akademia e Shkencave e RP të Shqipërisë, 1980. Version online (электронный ресурc). URL: http://www.fjalori.shkenca.org (дата обращения: 25.05.2019).

\section{References}

Apresyan 1986/1997 — Yu. D. Apresyan. Deyksis v leksike i grammatike i naivnaya model mira [Deixis in vocabulary and grammar and the naive model of the world]. Semiotika i informatika: Opera Selecta [Semiotics and informatics: Opera Selecta]. Iss. 35. Moscow: Russkie slovari, 1997. P. 272-298. (First published in: Semiotika i informatika [Semiotics and informatics]. 1986. Iss. 28. P. 5-33).

Beavers et al. 2010 - J. Beavers, B. Levin, S. W. Tham. The typology of motion expressions revisited. Journal of Linguistics. 2010. Vol. 46. No. 3. P. 331-377. DOI: 10.1017/S0022226709990272.

Daniel 2001 - M. A. Daniel. Padezh i lokalizatsiya [Case and localization]. A. E. Kibrik (ed.). Bagvalinskiy yazyk. Grammatika. Teksty. Slovari. [The Bagvalin language. Grammar. Texts. Dictionaries]. Moscow: Nasledie, 2001. P. 203-230.

Fillmore 1971/1983 - C. J. Fillmore. How to know whether you're coming or going. G. Rauh (ed.). Essays on deixis. Tübingen: Narr, 1983. P. 219-227. (First published as: C. J. Fillmore. How to know whether you're coming or going. K. Hyldgard-Jensen (ed.). Linguistik. Frankfurt a. M.: Athenäum Verlag, 1971. P. 369-379). 
Ganenkov 2002 - D. S. Ganenkov. Modeli polisemii prostranstvennykh pokazateley [Models of polysemy of spatial grammemes]. Unpublished graduation paper. Moscow: Moscow State University, 2002.

Klimenok 2018 - K. S. Klimenok. Prostranstvennyy deyksis v konstruktsiyakh s predlogom $n g a \mathrm{v}$ literaturnom albanskom yazyke: korpusnoe issledovanie [Spatial deixis in constructions with the preposition $n g a$ in literary Albanian: A corpus study]. Unpublished course paper. St. Petersburg: St. Petersburg State University, 2018.

Levontina, Shmelev 2005 - I. B. Levontina, A. D. Shmelev. Na svoikh dvoikh: leksika peshego peremeshcheniya v russkom yazyke [Na svoikh dvoikh 'on one's foot': Lexics of motion on foot in Russian]. A. A. Zaliznyak, I. B. Levontina, A. D. Shmelev. Klyuchevye idei russkoy yazykovoy kartiny mira [Key ideas of the Russian language picture of the world]. Moscow: Yazyki slavyanskoy kultury, 2005. P. 76-96.

Majsak 2005 - T. A. Majsak. Tipologiya grammatikalizatsii konstruktsiy s glagolami dvizheniya i glagolami pozitsii [Typology of grammaticalization of constructions with verbs of motion and position]. Moscow: Yazyki slavyanskikh kultur, 2005.

Nikitina 2009 - T. Nikitina. Subcategorization pattern and lexical meaning of motion verbs: a study of the source/goal ambiguity. Linguistics. 2009. Vol. 47. No. 5. P. 1113-1141.

Paducheva 2010 - E. V. Paducheva. Semanticheskie issledovaniya: Semantika vremeni i vida v russkom yazyke. Semantika narrativa [Semantic studies: Semantics of tense and aspect in Russian. Semantics of narrative]. $2^{\text {nd }}$ edn. Moscow: Yazyki slavyanskoy kultury, 2010.

Rakhilina 2008 - E. V. Rakhilina. Kognitivnyy analiz predmetnykh imen [Cognitive analysis of object names]. Moscow: Russkie slovari, 2008.

Walchli, Zúñiga 2006 - B. Walchli, F. Zúñiga. Source-Goal (in)difference and the typology of motion events in the clause. Sprachtypologie und Universalienforschhung. 2006. Vol. 59. No. 3. P. 284-303.

Zhugra 1986 - A. V. Zhugra. Aspektualnoe znachenie konstruktsiy s glagolom vij 'prikhodit' v albanskom yazyke [Aspectual meaning of constructions with the verb vij 'come' in Albanian]. A. V. Desnitskaya (ed.). Voprosy yazyka i literatury narodov balkanskikh stran [Issues of language and literature of the peoples of the Balkan countries]. Leningrad: Leningrad State University Publishing House, 1986. P. 54-61.

\section{Sources}

ANC 2011-2016 - M. Morozova, A. Rusakov, T. Arkhangelskiy. Albanian National Corpus (version 2011-2016). Available at: http://web-corpora.net/AlbanianCorpus (accessed on: 09.05.2019).

FGjSSh 1980 - A. Kostallari (kryered.) Fjalori i gjuhës së sotme shqipe: me rreth 41.000 fjalë [Dictionary of the Modern Albanian Language]. Tiranë: Akademia e Shkencave e RP të Shqipërisë, 1980. Version online. Available at: http://www.fjalori.shkenca.org (accessed on: 09.05.2019). 